\title{
DIME CÓMO HABLAS Y TE DIRÉ QUIÉN ERES \\ Claudia Albarrán*
}

RESUMEN: El texto examina cuáles son las características y rasgos del habla tanto de las mujeres como de los hombres; hace una valoración a partir de algunas de sus causas y concluye con una invitación a hacernos conscientes de la forma de expresarnos.

Palabras Clave: lenguaje, mujer, estudios lingüísticos, conducta comunicativa.
ABSTRACT: This article examines the distinctive characteristics and features of how both women and men speak. Based on this analysis, the author will make an assessment, and then invite the reader to become aware of their manner of speaking.

KEYWORDS: language, woman, linguistic studies, communicative behavior. 


\section{DIME CÓMO HABLAS Y TE DIRÉ QUIÉN ERES*}

Para mi madre, Consuelo Ampudia, quien desde hace siete años no puede hablar ni moverse, pero que desde su mutismo sigue enseñándome a valorar las palabras.

C onfieso desde ahora dos de las dudas que me han hecho titubear más de una vez durante la redacción de estas páginas: la primera es si tiene sentido tratar de definir cómo hablamos las mexicanas cuando, en este preciso momento, hay cientos de mujeres discriminadas, golpeadas, explotadas, violadas o asesinadas, sin que podamos vislumbrar todavía soluciones efectivas para ellas; la segunda es si podré aportar alguna idea original en estas páginas. Porque en México, y esto también debo decirlo de una buena vez, además de una profunda apatía por este tema, hay todavía

* Texto leído en la mesa redonda titulada "El lenguaje de la mujer mexicana", el lunes 8 de marzo de 2010, en el ITAM, con motivo de la celebración del Día Internacional de la Mujer. una ausencia de estudios dedicados a analizar este asunto que, hasta donde creo entender, está íntimamente relacionado con un problema que no parece ser prioritario para nuestros gobernantes, pero que tiene que ver directamente con la ineficacia de nuestro sistema educativo.

Todos hemos escuchado alguna vez la frase "una imagen dice más que mil palabras", y estoy segura de que ninguno se atrevería a dudar de su contundencia. Sin embargo, aunque pueda resultar un simple juego de palabras, quisiera darle una vuelta de tuerca y afirmar, también contundentemente, que una palabra puede decir más que mil imágenes; esto es, que el lenguaje que tanto mujeres como hombres utilizamos para expresarnos 
cotidianamente le transmite al otro una multiplicidad de facetas de lo que somos, pero también de lo que no somos o no podemos ser.

Como lo demuestra la cantidad de publicaciones que hay sobre el lenguaje y el género de los hablantes -en especial, en países como España, Rusia, Francia, Estados Unidos e Inglaterra, que tienen una amplia tradición en estudios lingüísticos-, hoy es imposible negar que las palabras que empleamos para relacionarnos le comunican a nuestros interlocutores una enorme cantidad de información, una diversidad de datos y de significados que están implícitos en el propio mensaje, aunque los hablantes no sean necesariamente conscientes de ello. De allí que se afirme que el decir de una persona no es sólo un vehículo para transmitir pensamientos y sentimientos, sino un espejo que refleja los rasgos distintivos de su identidad, como la edad, el nivel educativo, el estrato sociocultural, los usos y costumbres de la región que habita, la profesión, la ideología, la nacionalidad y, desde luego, el género.

A lo largo de más de cinco décadas, etnolingüistas, psicolingüistas y sociólogos de varias regiones del mundo, que se han dedicado a reflexionar sobre este fenómeno, parecen haber llegado a ciertos acuerdos sobre el conjunto de características que "actúan en el habla femenina y en la mascu- lina, (y) que funcionan como estereotipo de lo que la mayoría entiende o intuye como estilos asociados al género del que habla". ${ }^{1}$ Muchas de estas características se desprenden de nuestra fisiología -como el timbre, el tono o la potencia de voz-, mientras que otras se aprenden desde la infancia y se desarrollan o se atrofian a lo largo de la vida de cada individuo, de acuerdo con una serie de factores que van desde la educación recibida hasta el papel que cada uno está desempeñando en el momento en que interactúa con los demás.

Se dice que los primeros en estandarizar estos rasgos y en representar de una manera sistemática las tendencias del habla femenina fueron Ángel López García y Ricardo Morant, quienes, en su Gramática femenina, ${ }^{2}$ dedicaron sendos apartados a documentar el uso específico que las mujeres hacían de los pronombres o de las interjecciones, por ejemplo, así como a analizar por qué y cómo logramos imprimir en las palabras que pronunciamos esa supuesta carga afectiva que suele considerarse propia del habla femenina. De entonces a la fecha, las investigaciones, clasificaciones y cuadros comparativos entre el habla de las mujeres y los hombres han prolife-

${ }^{1}$ Cito el artículo de Ana Gisela Yépez Peñalver, "El habla de hombres y mujeres en el trabajo", en http://www.ucm.es/info/especulo/numero30/dlaboral.html, p. 1 (consultado el 12 de febrero de 2010).

${ }^{2}$ Publicado en España, Editorial Cátedra, 1991. 
NOTAS

rado, con variantes, aunque cabe aclarar que varios de los artículos y libros que hoy podemos encontrar en librerías, periódicos y revistas, tanto impresas como en Internet, tienden a exagerar esas diferencias, ya sea estigmatizando, extrapolando o privilegiando unas de otras, de una manera simplista, maniquea e incluso tendenciosa.

Mercedes Bengoechea, ${ }^{3}$ fuerte representante de esta corriente (que llamaré "clasificatoria") y autora de varios artículos, como "Mujeres/ hombres: el conflicto entre dos culturas" y "Lenguaje público y voz femenina", es una de las investigadoras que se ha dado a la tarea de reflexionar sobre aquellos rasgos estilísticos que, desde su punto de vista, son verdaderamente representativos del habla de cada género. En términos generales, afirma que el estilo que suele particularizar el decir de la mayoría de las mujeres occidentales (y, en concreto, las de clase media) es, primeramente, el deseo de incluir a las personas con las que conversamos, enfatizando la cercanía que tenemos con el interlocutor, lo que se traduce en el hecho de que las mujeres parecemos requerir de un preámbulo o de una suerte de antesala para iniciar el diálogo, y tendemos a hacerlo más amable

${ }^{3}$ Es profesora titular de sociolingüística en la Universidad de Alcalá e integrante del Grupo NOMBRA (Comisión Asesora del Lenguaje del Instituto de la Mujer) desde 1994. (menos hostil) mediante el empleo de fórmulas de cortesía, introduciendo preguntas o exclamaciones en el discurso, disculpándonos por nuestra poca habilidad para realizar tal o cual tarea o, simplemente, intercalando sonrisas como señal de que el canal de comunicación con nuestro interlocutor permanece abierto.

En segundo lugar, explica que solemos poner mucha atención a las palabras con las que nos expresamos y que somos más respetuosas de las normas gramaticales, porque nos preocupa el efecto que nuestro lenguaje tendrá sobre los demás. Esto, dice Bengoechea, se percibe en nuestra preferencia a utilizar un vocabulario estándar para evitar palabras vulgares, groserías o registros demasiado coloquiales.

Un tercer rasgo sería la multiplicidad de cambios que damos a la entonación y a la voz para indicar la proximidad que tenemos con nuestro escucha y para hacerle saber que no ocupamos un lugar privilegiado o superior a él. Esto explicaría la utilización de timbres de voz más o menos agudos, el empleo frecuente de sonidos, comentarios, diminutivos, expresiones "aniñadas" y exclamaciones del tipo mmm, ajá, claro, sí,por supuesto, que intercalamos constantemente en el discurso del otro, así como los "altibajos" y giros "emocionales" que damos a la plática para demostrar interés o cercanía. 
El cuarto puesto lo ocupa lo que la investigadora llama "búsqueda de intimidad", que se traduce en la necesidad que tenemos de narrar experiencias vitales y de abordar los asuntos desde una perspectiva más personal y afectiva, entre otros aspectos. Por último, añade que a las mujeres nos gusta desarrollar las temas de forma "cooperativa", por lo que generalmente interrumpimos a quien habla, sin espaciar nuestras intervenciones, hilvanando, aquí y allá, detalles, matices, recuerdos u otros aspectos paralelos, $\mathrm{o}$ incluso opuestos o fuera de tema, como si giráramos alrededor del asunto principal a lo largo de toda la conversación. ${ }^{4}$ Tal vez por esto se nos ha hecho la mala fama de ser parlanchinas, verborreicas y boquiblandas.

Respecto a los rasgos propios del estilo masculino, me limito simplemente a enumerar algunas de las características que ésta y otras especialistas sugieren, como el deseo constante de autoafirmación que los hombres suelen mostrar cuando sostienen un diálogo con las personas que participan en su conversación; la búsqueda permanente de objetividad en sus discursos y el distanciamiento que suelen establecer frente a sus inter-

${ }^{4}$ Para elaborar una breve descripción, me he basado en el artículo de Mercedes Bengoechea, titulado "La comunicación femenina. Claves, desde la perspectiva de género, para entender qué pasa cuando hablamos", publicado en el número monográfico Las mujeres y el lenguaje, revista Emakunde, septiembre, 2003, pp. 1-33. locutores; el desarrollo de temas de forma individualista (no colaborativa), sin importarles las reacciones de sus escuchas, así como el empleo de expresiones francas y directas que, ante los oídos de las mujeres, suelen sonar demasiado secas e incluso hostiles, pero que, según Bengoechea, son recursos frecuentemente empleados por los varones para evitar esa "solidaridad masculina" que tanto les disgusta, porque puede prestarse a malas interpretaciones, entre otros factores. ${ }^{5}$

Como dije, esta breve lista clasificatoria de estilos que la investigadora desarrolla en los ensayos citados ${ }^{6}$ no es sino una de las tantas propuestas que otros investigadores han elaborado de manera similar a ésta para tratar de establecer un patrón del habla tanto de mujeres como de hombres. Me refiero a autores reconocidos, cuyos títulos se han convertido en best sellers, como Los hombres son de Marte, las mujeres son de Venus, de John Gray; Asi hablan las mujeres y Cómo hablan las mujeres, de Pilar García Mouton; o Superando la soledad. Cómo vivir con ella y vencerla, de Ángeles Rubio Gil.

En términos generales, si bien han intentado fijar un canon definitorio de las conductas comunicativas

${ }^{5}$ Ibid., p. 9.

${ }^{6}$ Especialmente el referido en la nota 4. 
NOTAS

de hombres y mujeres, es posible afirmar que no se cansan de advertir que incluso sus propias clasificaciones deben tomarse con cautela, porque los cánones femeninos y masculinos respecto al uso de la lengua no son universales ni se valoran de forma idéntica en todas las culturas, tiempos, contextos, edades, clases sociales, profesiones o grupos políticos. Y es que un elemento de estilo que suele atribuirse al género masculino puede ser denigrante en determinado país o en determinado grupo social, mientras que, en otro, ese mismo comportamiento puede ser alabado en mujeres que voluntaria o involuntariamente han asumido como propio un rasgo que se creía típicamente "masculino" (como, por ejemplo, la franqueza).

Ni siquiera la misma mujer se comunica de igual forma a lo largo de todos los momentos de su vida, sino que varía sus tácticas verbales según las personas con las que se relaciona, el lugar en que se produzca la interacción, la tarea que lleve a cabo y la función que cumpla el habla en determinado momento [...] Lo que sí existe es un conjunto de variaciones discursivas que actúan como marcas en el habla femenina y en la masculina que se actualizan en textos concretos. ${ }^{7}$

${ }^{7}$ Cfr. Ana Gisela Yépez Peñalver, op. cit., p. 2.
La idea no es nueva. Ya desde 1990, Robert Bly, en su libro Iron John. A book about men, ${ }^{8}$ anunciaba un cambo de estilos, de papeles y de paradigmas sociales, al postular que el varón norteamericano comenzaba a dejar de ser el "iron John" que había sido hasta entonces, para convertirse en una suerte de "sweet John", es decir, un hombre más dulce, más comprensivo, más tierno, más débil y sensible, que al fin dejaba de ostentar su protagonismo patriarcal, para asumir con dignidad muchas de las expresiones y funciones que por tradición habían sido consideradas exclusivamente femeninas.

Recorriendo un camino opuesto, pero similar al del Bly de los años noventa, en años recientes ha surgido un nuevo grupo de pseudosicólogos y pseudoespecialistas en análisis lingüísticos, que ofrecen cursos y servicios en publicaciones de baja monta -como en muchas de las bien llamadas "revistas del corazón", en varios libros de autoayuda y en infinidad de páginas de Internet-para "masculinizar" el discurso de aquellas mujeres que, al dudar de sus capacidades, desean incorporarse al mundo empresarial o gubernamental, entrenándolas en el dominio de prácticas "varoniles" del habla, con la promesa de que sobrevivirán e incluso descollarán

${ }^{8}$ Se publicó en Estados Unidos, en la editorial Addison-Wesley Publishing Company, Inc, 1990. 
en medio de la terrible vorágine hombruna.

Sea como fuere, no cabe duda que, si bien las manifestaciones del decir parecen responder a patrones sociales de conducta y están condicionadas por el papel que cada uno desempeña en la sociedad, no son fijas ni existen en forma pura. Hay infinidad de matices y variantes que no nos permiten llegar a conclusiones únicas y definitivas sobre los rasgos definitorios del habla de las personas en general, ni sobre el habla de las mujeres, ni sobre el habla de "la mujer mexicana", ni sobre el nivel de asertividad que tiene un particular estilo de decir. Y mucho menos hoy, que, gracias a infinidad de factores - como el movimiento feminista, los métodos anticonceptivos, los avances científicos, la incorporación de la mujer al mundo del trabajo y las nuevas tecnologías, entre otros-nuestros horizontes se han ensanchado.

Una buena parte de mujeres mexicanas privilegiadas no estamos reducidas al mundo del hogar y de los hijos, ni fincamos nuestras metas personales en una anhelada promesa de matrimonio. Hemos comenzado a desarrollar y a fortalecer, de manera racional y consciente, una serie de destrezas para insertarnos plenamente en un mundo profesional que se antoja cada vez más exigente y competitivo, en el que requerimos echar mano de distintos recursos de expresión, de diversos registros y aptitudes para alcanzar nuestros objetivos. Hemos, pues, desbordado el estereotipo de lo exclusivamente "femenino", y nuestras formas de hablar y de escribir se han vuelto cada vez más neutras, más estandarizadas, más homogéneas o unisex, por decirlo de manera fácil.

Lamentablemente, aún hay millones de mexicanas que están excluidas de este discurso y sus funciones siguen restringidas en varios rincones de nuestro país. Muchas siguen mal alimentadas, ignorantes o deficientemente educadas; marginadas, enclaustradas entre cuatro paredes, explotadas tanto por los hijos como por el marido, sometidas al capricho de servidores públicos corruptos, sin tener todavía herramientas ni valor para salir de allí. ¿Podríamos analizar su lenguaje, su forma de hablar, su comportamiento estilístico bajo estándares similares a los que he descrito, cuando sabemos que la abnegación y el silencio son sus principales rasgos de identidad?

Lo que sí es imperdonable para las mujeres y los hombres que hemos tenido la oportunidad de hacer tres comidas al día, de dormir en una cama limpia, de bañarnos con agua caliente, de vestir ropa adecuada y hasta 
NOTAS

de marca, de llegar a la universidad, de saber otros idiomas, de viajar incluso, es expresarnos tan mal como lo hacemos, desconocer las palabras, desperdiciarlas con tanta facilidad, transmitir ideas empobrecidas, escribir y hablar por inercia (como si se tratara de un acto reflejo), mentir descaradamente y rehuir los compromisos adquiridos con la palabra dada, considerar el lenguaje como morralla insignificante de cambio, cuando es, precisamente, lo que constituye y define al sujeto que lo enuncia.

Porque, no obstante que el castellano tiene entre 300 mil y $400 \mathrm{mil}$ palabras, la gran mayoría de los jóvenes mexicanos sólo utiliza en promedio 200 palabras al día, entre las que se encuentran "idiolectos", como güey, neta, onda o chido, ${ }^{9}$ que repiten una y otra vez sin percatarse de las implicaciones que esto conlleva tanto para su futuro como para el de nuestro país. Entiendo que el chat, los mensajes de texto y los correos electrónicos han modificado las formas de escritura y han generado un nuevo lenguaje (escueto, simple, rápido y directo), que prescinde de los acentos, de la ortografía, de los signos de puntuación, que no distingue el empleo de

${ }^{9}$ Cfr. Ramón Sevilla T., "Mexicanos utilizan sólo 200 palabras para comunicarse", periódico Reforma (sección noticias), publicado el 20 de febrero de 2008, p. 4. mayúsculas y minúsculas, que viola, en fin, casi todas las normas gramaticales. Y está bien que así sea. Pero la repetición constante de un mismo acto se hace costumbre, y una mala costumbre, reiterada a lo largo de los años, sin conciencia ni preocupación, lleva a que estas prácticas se vuelvan vicios irreversibles.

Al empobrecimiento y a la poca importancia que las mexicanas y los mexicanos solemos darle a las palabras, debemos sumarle otros problemas más, como la ineptitud de nuestros gobernantes, el rezago que hay en los programas académicos, el lugar preponderante que nuestro sistema educativo otorga a la memoria, la carencia de recursos económicos y humanos que padecen las escuelas, la desmotivación y la falta de preparación de los maestros, el poco interés con el que los alumnos asumen sus tareas, por mencionar sólo algunos. Quienes hoy asisten a la escuela no sólo no aprenden, sino que desaprenden los pocos conocimientos que han adquirido a lo largo de su educación básica, hasta llegar a la universidad, y más tarde, al trabajo. Una vez allí, ya sea en puestos de menor compromiso, ya sea en cargos con mayor alcance empresarial, social o político, comienzan a transmitir, irresponsablemente, desde sus respectivas tribunas, con sus escasas palabras y una nula preparación, toda su ignorancia, sus errores, 
sus vicios, sus discapacidades, que seguramente tendrán serias repercusiones en las generaciones subsiguientes, sin que haya nadie que levante la voz para detenerlos.

No quisiera terminar estar notas sin ofrecer un ejemplo de lo que he dicho hasta aquí para que cada quien saque sus propias conclusiones sobre este tema. Se trata de un video de youtube, en el que se muestran los errores que cometió una poderosa mujer mexicana en la lectura original de su discurso frente al presidente Felipe Calderón el viernes 15 de mayo del 2009, día del maestro. ${ }^{10}$

${ }^{10}$ Véase video titulado "Elba Esther Gordillo. El remix epidem", en http://www.youtube.com/ watch? $\mathrm{v}=\mathrm{Odk} 2 \mathrm{oZJWCnI} \& \mathrm{NR}=1$ \#watch-main-area, (consultado el 28 de febrero de 2010). 
CITAM Derechos Reservados.

La reproducción total o parcial de este artículo se podrá hacer si el ITAM otorga la autorización previamente por escrito. 